\title{
Formative Learning Evaluation of university students as success factor
}

\author{
Olga Bombardelli \\ University of Trento (Italy)
}

\begin{abstract}
This paper deals with the impact of formative evaluation on the learning success of the university students. A lot of young people interrupt their academic career before the end of it or meet big delays and demotivation. That is due to many reasons; one of them is the lack of clear understanding of the expected outcomes. The aim of this paper is considering how a formative evaluation process with clear indicators for transversal skills together with consistent teaching forms may help students to reach the main aims of university studies. I'll focus on competences as learning to learn, scientific and critical thinking, initiative and entrepreneurship, active citizenship, communication and social skills. Different ways of assessing lead to reach different aims. This contribution includes an ongoing study, describes data drawn from the use of a portfolio and from a qualitative questionnaire with closed and open questions for self assessment filled-in by the students of the subject area group "Citizenship Learning" at the University of Trento. Intermediate results highlight the importance of articulating learning goals explicitely for improvement of the students outcomes.
\end{abstract}

Keywords: University teaching and learning; formative assessment; transversal competences; empowerment

\section{Introduction}

The present paper is motivated by the belief that all students should be equipped with the knowledge, skills, work habits, and character traits they will need to pursue good results in their studies and challenging careers after graduation, and that a failure to adequately prepare students effectively denies them opportunities, with potentially significant consequences for them and for our economy, democracy, and society. A complex mix of factors act upon, and are embedded in empowerment of students boths through teaching/ evaluation strategies and student-faculty interactions. The aims of university learning included in the Dublin Descriptors (2004) remind the need of a balanced development of learning.

Assessment is a crucial part in the acquisition of key competences but most current assessment methods have a strong emphasis on knowledge and do not sufficiently capture transversal skills and the attitudes of key competences, while these are regarded as increasingly important for 21st century learning. In this paper I discuss the importance of formative evaluation for sussessful learning and present a good practice in the use of a portfolio by students.

Methods of this paper are partly recognition of the most relevant studies on the topic choosing them according to the practicability and the efficacy of the proposals in the daily teaching experience, referring to international official documentation as well, and partly are linked to use of formative evaluation at the University of Trento based on the outcomes of an European Comenius project: ECLIPSE (European Citizenship Learning in a Programme for Secondary Education), conducted in the years 2011-2014 by six European partners (Germany, Italy, Portugal, Romania, Spain, UK). The methodology includes the use of qualitative formative assessment tools like portfolio and self evaluation questionnaire, keeping in mind that different ways of assessing lead to reach different aims in the enacted curriculum, and that evaluation forms are in interaction with teaching methods and with the curricula development. 
Assessment is the process instructors gather data about their teaching and their students' learning (Hanna \& Dettmer, 2004). There are formative, and summative assessment procedures. The goal of formative assessment is to monitor student learning to provide ongoing feedback by instructors, helping students to identify their strengths and weaknesses.

Summative Assessments has the goal to evaluate student learning by comparing it against some standards at the end of an instructional unit whereas no further revisions can be made. Types of Summative Assessment are mid-term exams, final examination (in oral or written form), tests at the end of course units, term papers, final projects, and presentations. Grades are usually an outcome of summative assessment: they indicate whether the student has an acceptable level of knowledge-gain.

Formative evaluations differ from summative exams which provide a static picture of students' learning and do afford students opportunities to adjust their study habits; it is confidential, ungraded and informal, and not used for purposes of tenure or promotion decisions. Such evaluation is typically conducted during the development or improvement of a program or course; it is accompanied by instructional feedback that enables students to make learning adjustments and improve future work.

\section{Aims and Educational strategies}

The assessment of transversal skills is mostly done in implicit form. Teachers ask for transversal skills, anyway most of them pay insufficient attention to clarify what they appreciate and neglect developing them esplicitely. Althoughs several main skills are not easy to define teachers should be able to articulate learning goals more intentional, especially about teaching cross-disciplinary skills. For example, in a science course students might be required to learn research methods that can also be applied in other disciplines.

Discussion and exchange among teaching persons help agreement, while the specific skills may be defined, categorized, and determined differently from person to person, and that is confusing for learners. In turn, students can benefit from frequent and thoughtful feedback that promotes their own self-awareness and self-regulation of their learning process. Formative evaluations encourage an ongoing, reciprocal exchange between faculty and student(s) that can move students toward self-monitoring of their work and intellectual persistence; it encourages students to learn from mistakes and empower them for self-efficacy.

Learning success requires the acquisition of the fundamental basic skills such as literacy, numeracy skills, the analysis and summary abilities, the written and oral communication or the ability to organize and plan the work. Articulating general, technical, and scientific concepts in verbal, written, and graphic forms, or using sophisticated technologies, software programs, and multimedia applications are an extension of the expected outcomes.

Skills refer to a broad set of knowledge, work habits, and character traits that are believed by educators, parents, employers, and others to be critically important in today's world. Transversal skills like (A) learning to learn, included scientific culture, and (B) entrepreneurship are now increasingly needed. Very important is the development of attitudes and dispositions like (C) active citizenship, (D ) social, and intercultural competence (respect for diversity: gender, cultures, religion, age, learning styles etc.), cross-national perspektives replacing stereotypes, developing a sense of belonging to one's own community, and to the world.

(A) Learning to learn is the ability to organise one's own learning, effective 
management of time and information. This competence includes awareness of one's learning process and needs, identifying available opportunities, and the ability to overcome obstacles in order to learn successfully. It means gaining, processing and assimilating new knowledge and skills as well as seeking and making use of guidance. It requires an individual to know and understand his/her preferred learning strategies, the strengths and weaknesses of his/ her skills and qualifications, and to be able to search for the education and training opportunities and guidance (Recommendation 2006/962/EC).

This requires effective management of one's learning, career and work patterns, and, in particular, the ability to persevere with learning, to concentrate for extended periods and to reflect critically on the purposes and aims of learning. Individuals should be able to dedicating time to learning autonomously and with self-discipline, but also to work collaboratively as part of the learning process, draw the benefits from a heterogeneous group, and to share what they have learnt. A positive attitude includes the motivation and confidence to pursue and succeed at learning throughout one's life, the desire to apply prior learning and life experiences and the curiosity to look for opportunities to learn.

(B ) Initiative and entrepreneurship include self knowledge, and self-planning, problem solving, coping with ambiguity, assessing risks, informed decision-making;

(C ) Education for active Citizenship includes knowledge of contemporary events, as well as the main events and trends in national, European and world history. In addition, an awareness of the aims, values and policies of social and political movements should be developed.

Responsible citizenship means participation, information, for the personal life, and for democracy. It implies supporting pupils to develop the competences of acquiring information, using appropriate data from a range of sources, selecting, interpreting, and evaluating them (autonomy in looking for information, choosing sources, awareness of different points of views, precision, etc.).

(D) Social competentce requires skills for working with others, conflict prevention and solution, participating in the social life with a supportive attitude, showing personal and group involvement Propose solutions that require their involvement as individuals and as a group, caring for community assets.

There is a need to a profound and lasting change in teaching methodologies. Competence-based teaching/ learning goes hand in hand with developing transversal competences as well, besides providing information. Educational strategies such project-based learning tend to be cross-disciplinary in nature, and students may have to use a variety of applied skills, and new ways of analyzing and processing information, while also taking initiative, thinking creatively, planning out the process, and working collaboratively in teams with other students.

Educational processes, curriculum content are thaught successfully with innovative teaching /learning methods, adopting strategies like interactive, experiential and reflexive learning, using a multi-perspective approach, to support students both to acquiring information, and to work with documented and coherent argumentation, linking formal and non formal learning. Useful are strategies like lecturing, interactive lectures, seminars, student-led seminars, group work, case studies, small group exercises, blended learning (MOOC ecc.), tutoring and peer tutoring, project work, caring for classroom discussions and open debates, giving reasoned arguments and motivation for the own opinions. Cooperative learning and jigsaw technique allow the students to assume some responsibilities as a member of a group; enquiry tasks for 
students, interviews, school journals on line, work experiences are very helpful for the development of competences.

Curriculum materials and resources, media inputs (films, TV, videos, radio, Internet, newspaper, books, games), teaching tools like maps, schoolbooks, fotocamera, etc. are useful to support teaching. Essential is media literacy (search and selection of information on the topics, interpreting the media messages, use of the media in an active way as a producer of media content).

The working climate, the daily practices refer mainly to a system of attitudes, values, norms, beliefs, principles, rules, teaching methods and organizational arrangements which have to be consistent with the desired aims.

Exchange of good practices among professors in the different countries improves evaluation practices as well, analysing testing materials, and developing new ones. Students in different places can perfom bilateral work including discussions and production of common results. Cooperation among the schools can take place face to face, with meetings and visits, and on line in videoconference and webinars, pen/ mail friendships etc.; of course ICT teaching is not expected to substitute face to face teaching.

\section{Formative Assessment}

The old maxim “if it isn't tested it isn't taught” is quite true. For the learners, assessment shows what is valued as a learning outcome. The assessment methods have a major influence on how the key competences are taught, and therefore, on what learners learn (Looney, 2009).

The way in which the outcomes have been agreed upon, described and assessed, may influence what the learners are motivated to achieve. However, some assessment practices may damage motivation and self-esteem, especially for 'low-achievers'.

Some strategies of assessment stress passive repetition, on the contrary independent learning implies a real understanding of the learning process by the students (metacognition). Self knowledge, and self-planning include awareness of their own skills by the learners, improving their self confidence, fostering the interest and the energies in a gradually self-regulating plan (ex. the student portfolio). The teacher will report back to the students about the results of the evaluation, providing feedback during the instructional process, while learning is taking place. Formative assessment also helps to identify the intended outcomes as well as any unintended outcomes of instruction, and are basis to ensure that students have sufficient opportunities to achieve them.

Assessment involves a variety of methods and techniques. Formative Evaluation of Student Learning includes any form of classroom interaction that generates information on student learning, which is then used by faculty and students to fine-tune their teaching and learning strategies.

Types of Formative Assessment are formal and informal, especially: (a) observation, (b) interaction, (c) production of midterm outcomes, (d) selfevaluation forms:

(a) Teachers practice direct observation of in-class activities (teamwork, the way pupils organize work), of students' skills and attitudes, and the product, with the aid of records and rating scales of observation, check lists, assessment scales.

(b) Informal and structured mid-term feedbacks ensure students thet they are on track. It can be formative oral interviews, 'question and answer sessions', both formal, planned and spontaneous, discussion board responses (on content-specific prompts), directed paraphras after working through a topic, asking students to explain the content to a lay audience in their own words. An instructor can do his/her own formative 
assessment by having students respond to a mid-term questionnaire. Pre-tests on content and abilities (including several types of questions: multiple-choice, true-false etc.), clickers may be used as well.

As the time is very short in the University modules, lecurers may use 'one-minute papers', checking student understanding in a lesson by asking them to take out a sheet of paper and take one minute to, for example, write down an explanation of a concept, or submit one sentence identifying the main point of a lecture.

Techniques like polls/surveys gathering of data on student opinions, attitudes, or confidence in understanding, even online, can help students develop skills to monitor their own learning; lecture wrappers are questions at the beginning of class about what students anticipate getting out of a lesson and/or questions at the end of class about the key points of the lesson.

(c) In-class activities, class deliverables are opportunities where students informally present their results. Open book questions give the chance to assess not only what students remember and allow to check how they are able to use information and to perform organized and systematic reasoning. Homework exercises and homework wrappers include questions about students' confidence in applying their knowledge and skills both before and after completing an assignment. Having students work in pairs or small groups to solve problems creates space for powerful peer-to-peer learning. Alternative forms of work and formative assessment are preparing an exhibition, a poster, reflections journals; filming and exchanging DVD, Podcasts, etc.

(d ) Self-assessments forms, identifying skills and competencies, can be face to face or developing a portfolio as a way for students to see their progress. Instructors can roam the classroom as students work, helping those who get stuck and guiding those who are headed in the wrong direction.

Diagnostic strategies can help teachers to identify students' current knowledge of a subject, their skill sets and capabilities, and to clarify misconceptions; they facilitate the evaluation of competences for the student, as they clearly perceive the different dimensions that are being evaluated in each activity, increasing, with that, their academic performance.

\section{An example of formative assessment in education for citizenship: a portfolio}

Citizenship Education aims to the development of the students tranversal competences, gives information, encourages kritical knowledge, in order to avoid acritical adherence to a specific model. It is never indoctrination, instead it is an effort for reflexion and documented coherent decision making.

An European Comenius project ECLIPSE (European Citizenship Learning in a Programme for Secondary Education) (Bombardelli, Santana, 2014), which I coordinated, developed a Portfolio for the pupils as a monitoring tool, used in the six partner countries at least in three schools each. It helps pupils to think about their own development focussing on (1) Political Culture (I know my rights and responsibilities, I am aware of social and cultural diversity, I actively participate in democratic life), (2) European Citizenship (I know about the European Union, I understand the rights and duties of citizens); (3) Skills needed to co-exist (I can prevent conflicts and solve them non-violently, I can give opinions, discuss and debate, I can understand others and communicate well), Values needed to co-exist (I understand the importance of selfesteem, autonomy and responsibility, I have respect for others and reject discrimination), (4) Participation in local environment, I get involved in school and 
local community groups, I participate in sports teams, citizenship and solidarity associations), (5) Entrepreneurship (I show initiative and autonomy, I can communicate and co-operate in a team, (6) Active learning and self-planning (I can plan, manage and organise my time, I can take constructive criticism).

The ECLIPSE portfolio has been revised for the level of University students, and has been used at the University of Trento; about the effectiveness of this work students answered a questionnaire/ selfevaluation sheet, focussing mainly on learning processes; the major outcomes are measured through group discussion as well, integrated by individual dialogue when it has been asked for by the students. Respondents are twenty students from different geographic areas; as result about $90 \%$ declared the high impact of the portfolio on their learning, while $10 \%$ of them required extra help to understand what they were expected to perform.

The outcomes of education for citizenship are difficult to be assessed; I provide here general tabular results (Table 1).

Table 1. Level of learning confidence by the students in the 6 sections of the portfolio

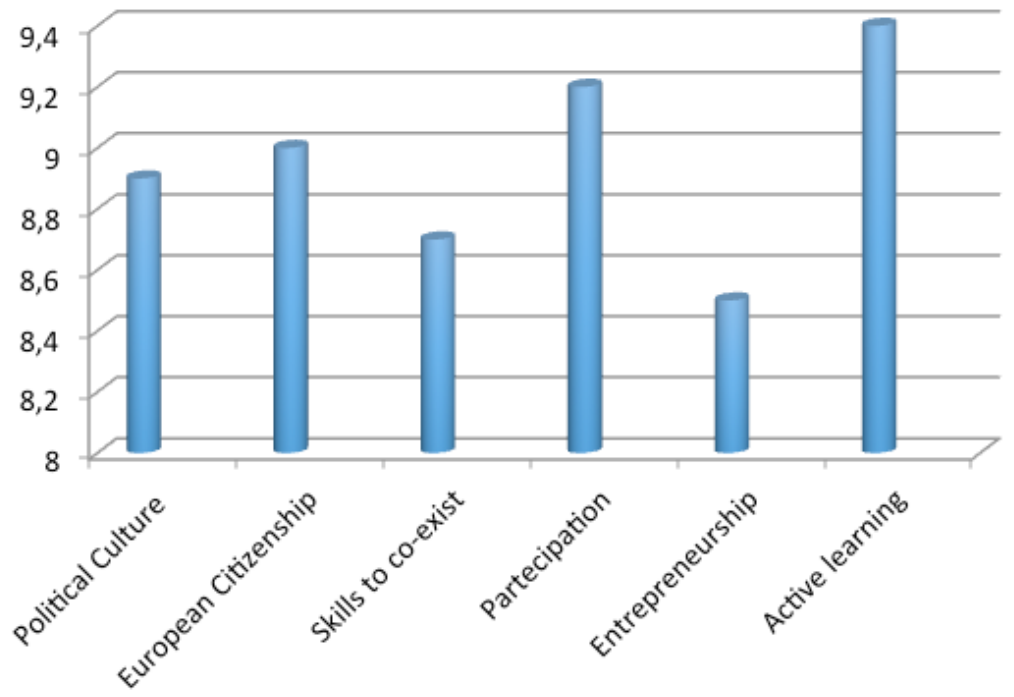

Monitoring transversal skills (e.g. learning processes: memorising, selecting information, etc. s. http://events.unitn.it/ecein) and values developes the ability to identify one's strengths and weaknesses. The obtained results look promising, anyway the work of the performed study has been done with a small group; during the next years bigger groups of students will cooperate in this project. Until now we can say that this approach has given better results in term of grading at the end of the module, which can be explained both by more interest by the involved students and by more detailed clarification of the transversal skills through formative evaluation.

\section{Conclusions}

While there is broad agreement that today's students need high skills, and that crossdisciplinary competences such as writing, critical thinking, self-initiative, active citizenship, and social skills are essential to success in higher education, in modern workplaces, and adult life, there is still a compliance gap among needs and results in tertiary education. Clear explanation of indicators to reach the main aims and formative evaluation help students to understand clearly what they are ecpected to learn; benefits 
are more likely when evaluation techniques are accompanied by providing feedbacks and instruction.

The present study highlights that learning results at the University are higher when there is a clear conceptual framework of expected learning outcomes; it implies the need to develop further work concerning formative evaluation in relation to competence-based curricula. Teaching persons need to be convinced of the importance of this task, to know how to manage this new approach to learning, to master effective formative assessment approaches, and to be aware of the opportunity of explaining explicitely transversal skills and the ways of assessing them.

\section{References}

Anderman, E.M., Austin, C.C., and Johnson, D.M. (2002). The development of goal orientation. In: The Development of Achievement Motivation, ed. A. Wigfield and J.S. Eccles, 197-220. New York Academy Press.

Bombardelli, O. (2010). Education for responsible citizenship and sustainable development in Lifelong Learning and Active Citizenship, London: CiCe, 364-371.

Bombardelli, O. (2014). Learning citizenship competences: the project eclipse.

Bombardelli, O., Santana, L. (2014). European citizens are growing up. Madrid: EOS.

Dublin Descriptors (2004) http://www.tcd.ie/teaching-learning/academicdevelopment/assets/pdf/dublin_descriptors.pdf (last access January 2015).

ECLIPSE (European Citizenship Learning in a Programme for Secondary Education), eclipse.lett.unit.it

Hanna, G. S., Dettmer, P. A. (2004). Assessment for effective teaching: Using contextadaptive planning. Boston, MA: Pearson A\&B.

Recommendation of the European Parliament and of the Council of 18 December 2006 on key competences for lifelong learning (2006/962/EC).

Kerr, D., Sturman, L., Schulz, W., Burge, B. (2010). ICCS 2009 European report: Civic knowledge, attitudes, and engagement among lower-secondary students in 24 European countries. Amsterdam: IEA (International Association for the Evaluation of Educational Achievement).

Kingston, N., Nash, B. (2011). Formative Assessment: A meta-analysis and call for research. Educational Measurement: Issues and Practice, 30(4). 28-37.

Looney, J. (2009). Assessment and Innovation in Education: OECD Working Paper No. 24, Paris; OECD/CERI, 11-16. 